\title{
Surface runoff features on Mars: Testing the carbon dioxide formation hypothesis
}

\author{
Sarah T. Stewart ${ }^{1}$ \\ Division of Geological and Planetary Sciences, California Institute of Technology, Pasadena, California, USA
}

Francis Nimmo
Department of Geological Sciences, University College London, London, UK
Received 5 February 2001; revised 23 August 2001; accepted 20 September 2001; published 28 September 2002.

[1] Fresh gully-like features on Mars strongly suggest that fluid flowed on the surface in the recent past. Here we consider the possibility that $\mathrm{CO}_{2}$ vapor-supported flows formed the gullies. We find that neither condensed $\mathrm{CO}_{2}$ nor $\mathrm{CO}_{2}$ clathrate hydrate are likely to accumulate in significant quantities in the Martian crust. In addition, if condensed $\mathrm{CO}_{2}$ were present under lithostatic pressures, exposure to the atmosphere would produce features analogous to terrestrial pyroclastic flows, not surface runoff. Finally, the source volume of $\mathrm{CO}_{2}$ required to support a flow excludes clustered or episodic gully formation. Therefore, we conclude that $\mathrm{CO}_{2}$ cannot have formed the gullies. In light of these results, liquid water flow remains the preferred formation mechanism for the recent surface runoff features. INDEX TERMS: 6225 Planetology: Solar System Objects: Mars; 5410 Planetology: Solid Surface Planets: Composition; 5415 Planetology: Solid Surface Planets: Erosion and weathering; 5470 Planetology: Solid Surface Planets: Surface materials and properties; KEYWORDS: Mars, gullies, seepage, runoff, carbon dioxide, water

Citation: Stewart, S. T., and F. Nimmo, Surface runoff features on Mars: Testing the carbon dioxide formation hypothesis, J. Geophys. Res., 107(E9), 5069, doi:10.1029/2000JE001465, 2002.

\section{Introduction}

[2] High-resolution photographs of surface runoff and seepage features on Mars [Malin and Edgett, 2000] provide a compelling case for recent surface fluid erosion. In particular, the origin of the gully-like features, originating at about two hundred meters below the top of the slope, raises the possibility that water was present, for at least short time periods, at shallow depths in recent history.

[3] The geomorphic evidence for fluidized flow includes a head alcove, main and secondary V-shaped channels, and depositional aprons (see Figure 1 and Malin and Edgett [2000]). The runoff features are superimposed upon sand dunes and polygonal terrain and lack overlying impact craters or dust cover, implying that they are relatively young formations. The gullies are found at mid to high latitudes $\left(30^{\circ}-70^{\circ}\right)$ on steep slopes along the walls of impact craters, polar pits, and valleys. The initial survey of these features shows a preference for formation on poleward-facing slopes. The V-shaped channels have a width and depth of 10 's of meters and are a few hundred meters to over a kilometer in length. In many examples, several to hundreds of gullies on a single slope, spaced at 10 's -100 's m

\footnotetext{
${ }^{1}$ Now at Geophysical Laboratory, Carnegie Institution of Washington, Washington, D. C., USA.

${ }^{2}$ Also at Division of Geological and Planetary Sciences, California Institute of Technology, Pasadena, California, USA.

Copyright 2002 by the American Geophysical Union. 0148-0227/02/2000JE001465\$09.00
}

intervals, originate from an apparent seepage layer, a few hundred meters below the top of the slope.

[4] Liquid water is widely accepted as the cause of many ancient surface features on Mars, such as the valley networks, channels flowing away from crater rims, and possibly a northern ocean [Carr, 1996]. The hypothesis that liquid water formed these recent features is problematic since current geothermal models of the Martian crust put the $\mathrm{H}_{2} \mathrm{O}$ liquid stability depth at several kilometers below the surface [Clifford, 1993; Mellon et al., 1997]. Water could be stable at shallow depths if there were significantly higher internal heat flux, substantial salt content, extremely low thermal conductivity material, and/or higher temperatures at the surface [Mellon and Phillips, 2001; Knauth et al., 2000]. Alternatively, liquid water could be brought to the surface rapidly from depth, perhaps through processes similar to terrestrial volcanism [Gaidos, 2001].

[5] Recently, however, carbon dioxide, in pure or clathrate hydrate form, has been suggested as an alternative to liquid water formation of both large and small-scale features [Musselwhite et al., 2001; Max and Clifford, 2001; Jöns, 2001; Parsons, 2001; Hoffman et al., 2001; Hoffman, 2000a, 2000b, 2001; Kargel et al., 2000; Komatsu et al., 2000; Baker et al., 2000; Draper et al., 2000; Longhi, 2000]. The imaging evidence for fluid erosion under the present climatic conditions has raised the question of the role of carbon dioxide in sculpting the Martian surface. In this paper, we examine the criteria for the stability of condensed $\mathrm{CO}_{2}$ and describe the geologic processes that may emplace carbon dioxide or $\mathrm{CO}_{2}$ clath- 


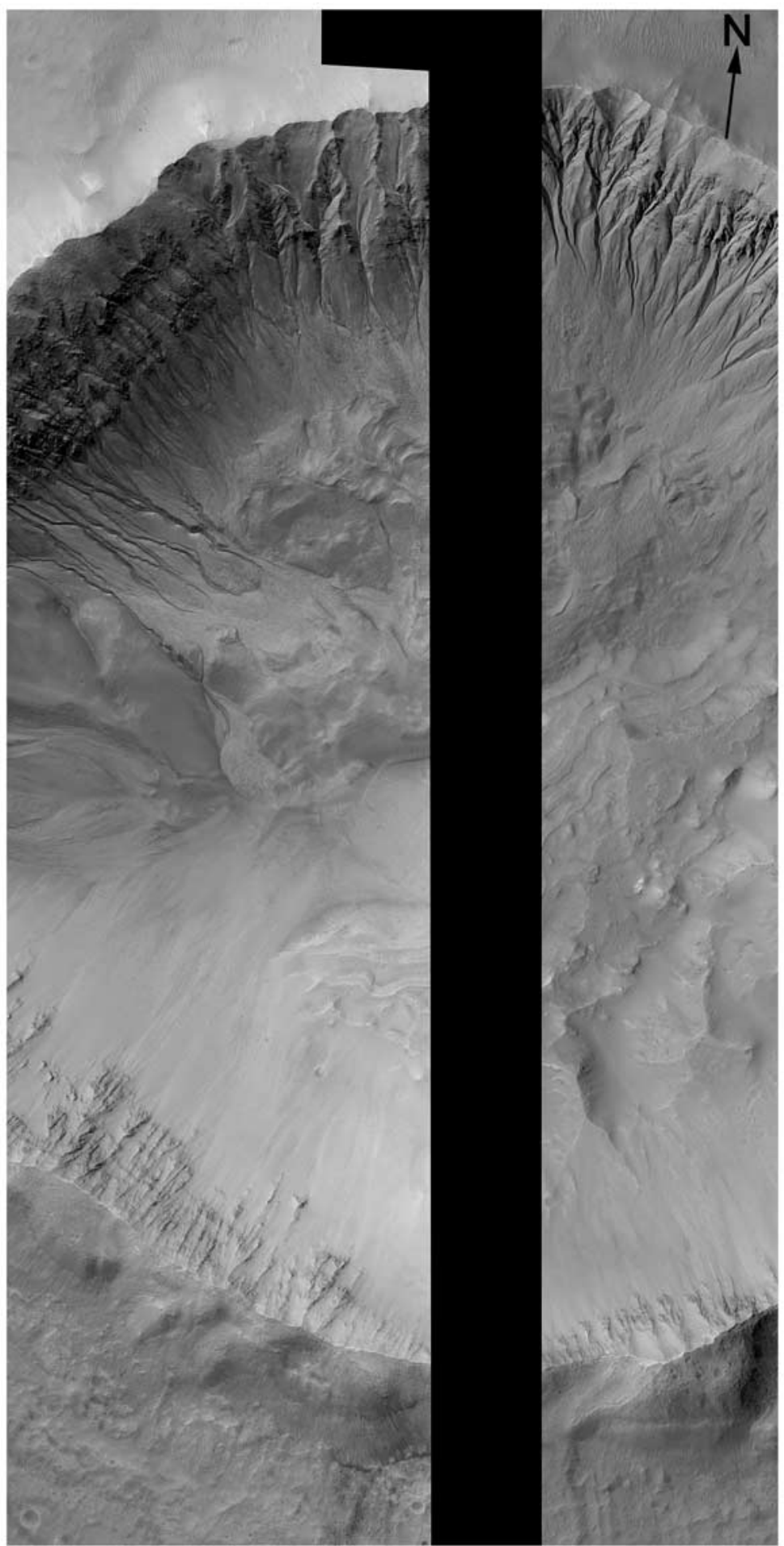

Figure 1. Example of Martian gullies, preferentially on the poleward-facing slope, in a 12-km diameter crater in Gorgonum chaos, near $37.4^{\circ} \mathrm{S}$ and $168.0^{\circ} \mathrm{W}$. The solar illumination direction is from the upper left. Note the close spacing of the gullies, which have deep V-shaped channels and originate at the same level in the crater wall. The combined width of the images is approximately $7.6 \mathrm{~km}$. A close-up view of the depositional aprons is shown in Figure 5. The figure is a composite of 3 Mars Orbiter Camera images. The center of the crater was not imaged. [MGS MOC Release No. MOC2-241, 22 June 2000, NASA/ JPL/MSSS.] 


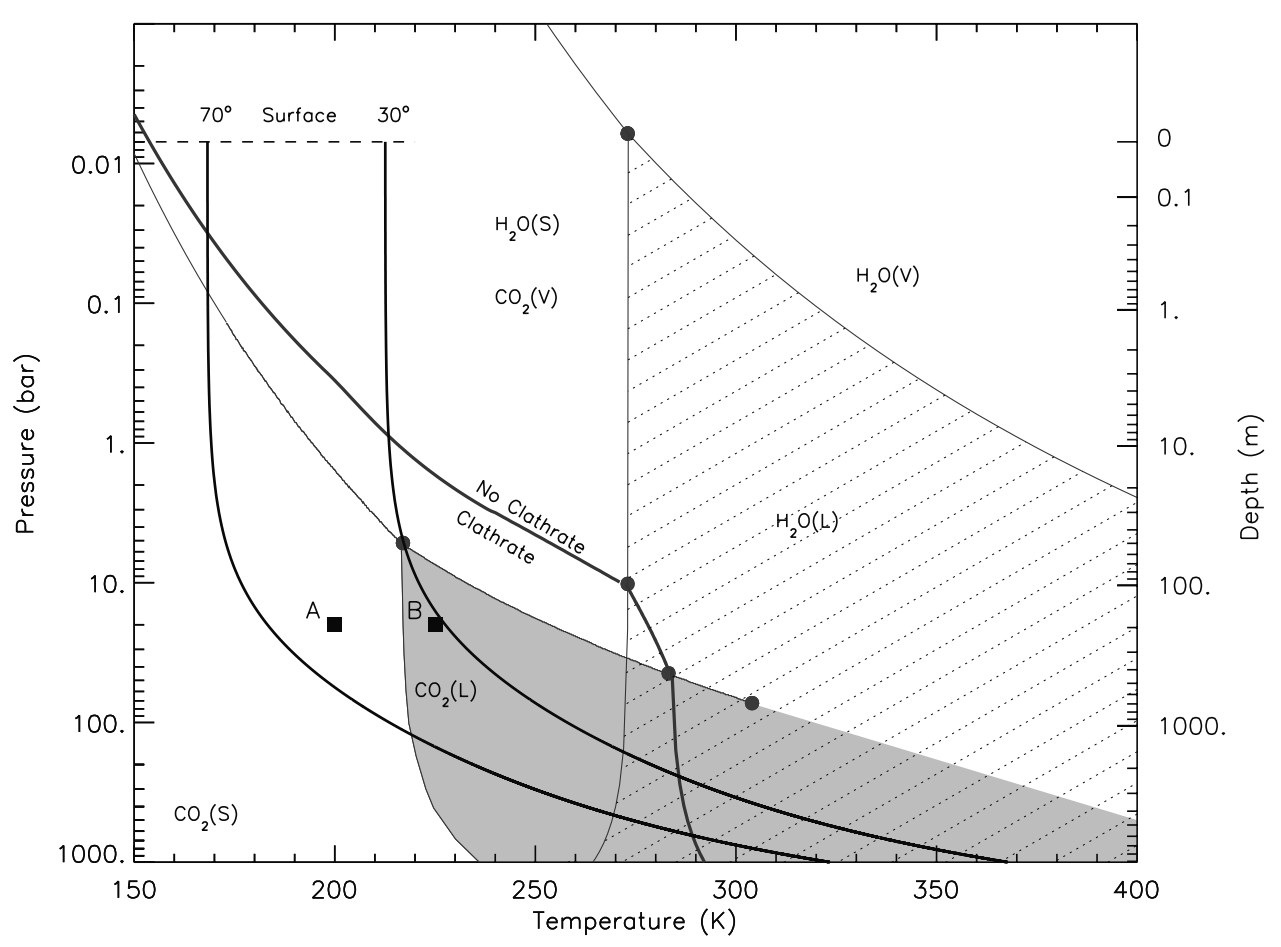

Figure 2. $\mathrm{H}_{2} \mathrm{O}-\mathrm{CO}_{2}$ phase diagram with Martian geotherms at 30 and $70^{\circ}$ latitude (labeled thick solid lines), the observed latitude range of the gullies. The geotherms imply that solid or liquid $\mathrm{CO}_{2}$ would be stable under lithostatic pressures and temperatures near the surface (within 100's m). Points A and B represent hypothetical $\mathrm{CO}_{2}$ reservoirs in the crust at the gully source depth and correspond to the points labeled in Figure 3. Phase diagrams compiled from Span and Wagner [1996], Wagner et al. [1994], and Miller [1974], and the vapor, liquid and solid stability fields are labeled V, L, and S respectively.

rate hydrate in the Martian crust. We consider whether gassupported flows would reproduce the morphology of the gully-like features and determine the mass of $\mathrm{CO}_{2}$ necessary to support such a debris flow.

\section{Carbon Dioxide Hypothesis}

[6] The hypothesis that solid or liquid $\mathrm{CO}_{2}$ could form fluid flow features on Mars is based on comparison between theoretical geothermal profiles and the equilibrium phase diagrams of carbon dioxide and $\mathrm{CO}_{2}$ clathrate hydrate. The geotherms shown in Figure 2 suggest that condensed $\mathrm{CO}_{2}$ could be stable at depths of $\sim 100 \mathrm{~m}$ at mid-latitudes. The geothermal profiles assume an internal heat flux of $30 \mathrm{~mW} \mathrm{~m}^{-2}$ (see review by Clifford [1993]). The thermal conductivity increases and porosity decreases exponentially from surface values of $0.3 \mathrm{~W} \mathrm{~m}^{-1} \mathrm{~K}^{-1}$ and $10 \%$ to $3.0 \mathrm{~W} \mathrm{~m}^{-1} \mathrm{~K}^{-1}$ and $0 \%$ at depth, respectively, with a decay constant of $2820 \mathrm{~m}$ [after Clifford, 1993]. The surface temperatures are taken from Fanale et al. [1986], and the surface pressure is 7 mbar. The pressure-depth relationship is calculated assuming a $1000 \mathrm{~kg} \mathrm{~m}^{-3}$ volatile fills the pore spaces and a rock density of $3000 \mathrm{~kg} \mathrm{~m}^{-3}$.

[7] Direct comparison between a geotherm and the phase diagram is only appropriate if the $\mathrm{CO}_{2}$ fugacity, $f_{\mathrm{CO}_{2}}$ (equivalent to partial pressure for ideal gases), is equal to the lithostatic pressure, $P_{L}$. If the $\mathrm{CO}_{2}$ is stored within pore spaces in the regolith, the pores must be filled to bear any load. Otherwise, the regolith matrix supports all of the overburden pressure, the fugacity of the interstitial $\mathrm{CO}_{2}$ would remain close to the atmospheric pressure, and the assumption of $f_{\mathrm{CO}_{2}}=P_{L}$ would not be satisfied. Therefore, solid $\mathrm{CO}_{2}$ in contact with the atmosphere, regardless of the depth in the crust, is only stable at equilibrium temperatures of about $150 \mathrm{~K}$. Liquid $\mathrm{CO}_{2}$ is not stable with the current atmosphere anywhere on Mars.

[8] The conditions for stability of condensed $\mathrm{CO}_{2}$ at average subsurface temperatures show that the equilibrium fugacity of $\mathrm{CO}_{2}, P_{\text {equil }}$, may be orders of magnitude larger than the atmospheric pressure, $P_{\mathrm{atm}}$. For the surface temperatures over the latitudes where the gullies are observed, $P_{\text {equil }} \geq 10 P_{\text {atm }}-10^{3} P_{\text {atm }}$ (see Figure 2$)$. Next, we examine possible formation mechanisms and the stability of solid $\mathrm{CO}_{2}$ or $\mathrm{CO}_{2}$ clathrate hydrate in the crust.

\subsection{Pure $\mathrm{CO}_{2}$ Emplacement Mechanisms}

[9] The two most likely sources of carbon dioxide in the crust on present-day Mars are the atmosphere and outgassing magmas. Although early investigations into the composition of the polar caps favored pure $\mathrm{CO}_{2}$ or $\mathrm{CO}_{2}$ clathrate hydrate [cf. Dobrovolskis and Ingersoll, 1975; Armistead, 1979, and references therein], the caps are no longer thought to be a large reservoir for $\mathrm{CO}_{2}$. Limits on the perennial amount of $\mathrm{CO}_{2}$ in the polar caps range from $\sim 10$ mbar equivalent global atmospheric pressure based on thermal stability arguments [Mellon, 1996] to none whatsoever based on $\mathrm{CO}_{2}$ rheology experiments [Nye et al., 2000].

[10] If the early atmosphere on Mars were more massive, precipitation could have introduced solid or liquid $\mathrm{CO}_{2}$ into 
the crust. But current models of the evolution of the Martian atmosphere do not suggest that the early pressure was greater than about 5 bar [cf. Haberle et al., 1994; Fanale et al., 1992] at which point $\mathrm{CO}_{2}$ precipitation begins to play an important role. Even if there were a thicker, warmer atmosphere in the past, it would be difficult to store $\mathrm{CO}_{2}$ in the crust through to the present day. Solid or liquid $\mathrm{CO}_{2}$ would have to be introduced into the crust and then sealed from the atmosphere to maintain a stable $\mathrm{CO}_{2}$ fugacity as the climate changed and the atmospheric pressure decreased.

[11] Assuming that solid or liquid $\mathrm{CO}_{2}$ were introduced into the crust in the past, we examine the timescales for equilibration with the atmosphere. Any liquid $\mathrm{CO}_{2}$ exposed to decreasing atmospheric pressure would cool as it boiled and ultimately freeze. The temperature of a block of solid $\mathrm{CO}_{2}$ at the surface will be maintained at $150 \mathrm{~K}$ by the balance between sublimation and the incident solar radiation. Other heat sources, such as conduction, would be relatively inefficient, and other cooling mechanisms, such as convection, are less efficient than sublimation on the surface of Mars [Hecht, 2002]. Therefore, we may estimate the sublimation rate, $r_{s}$ in $\mathrm{m} \mathrm{s}^{-1}$, from insolation by

$$
r_{s}=\frac{S_{\odot}(1-A)}{L \rho_{s}},
$$

where the solar constant at Mars, $S_{\odot}$, is $590 \mathrm{~W} \mathrm{~m}^{-2}$, and the density of solid $\mathrm{CO}_{2}, \rho_{s}$, is $1560 \mathrm{~kg} \mathrm{~m}^{-3}$ [Quinn and Jones, 1936], and the latent heat of sublimation, $L$, is $613 \mathrm{~kJ} \mathrm{~kg}^{-1}$ (at $121 \mathrm{~K}$ [Miller and Smythe, 1970]). The albedo of $\mathrm{CO}_{2}$, $A$, is estimated from the polar cap albedo, with a maximum of about 0.6 [Kieffer, 1979; James et al., 1992]. The maximum sublimation rate is over $7 \mathrm{~m} \mathrm{yr}^{-1}$ for full solar insolation, decreasing by a factor of $(1-\cos \theta)$ for the effective latitude, $\theta$ [see also Kieffer et al., 2000, Table 3]. Hence, except for the Martian polar regions or permanently shaded regions on Mars where condensation may balance sublimation, solid $\mathrm{CO}_{2}$ on the surface would sublimate on a geologically instantaneous timescale.

[12] In general, the subsurface equilibrium temperature will exceed the stability temperature with the present atmosphere (Figure 2). Removal of subsurface $\mathrm{CO}_{2}$ will depend on the rates associated with thermal equilibration in the crust and diffusion to the atmosphere. The timescale, in seconds, for conductive heating over a length scale, $l$, is estimated from the thermal diffusion timescale

$$
t_{l} \sim \frac{l^{2} \rho_{s} c_{p}}{K}
$$

where $K$ is the thermal conductivity of solid $\mathrm{CO}_{2}$, about 0.6 $\mathrm{W} \mathrm{m}{ }^{-1} \mathrm{~K}^{-1}$ [Kravchenko and Krupskii, 1986], and $c_{p}$ is the specific heat capacity, about $1000 \mathrm{~J} \mathrm{~kg}^{-1} \mathrm{~K}^{-1}$ [Washburn et al., 1929], at $150 \mathrm{~K}$. For an intimate $\mathrm{CO}_{2}$-rock mixture, the conduction timescale will be limited by the material with lower thermal diffusivity, $K /\left(\rho c_{p}\right)$. The thermal conductivity of solid $\mathrm{CO}_{2}$ is less than or similar to porous rock or particulates [Clifford, 1993, and references therein] but $\mathrm{CO}_{2}$ is also less dense, so the timescales will be of the same order of magnitude. The timescales for heating a parcel of solid $\mathrm{CO}_{2}$ from the stability temperature of $150 \mathrm{~K}$ to the equilibrium geothermal temperature of 170-210 K (see
Figure 2) of the surrounding rock are about $0.03 \mathrm{~s}, 0.08 \mathrm{yr}$, and $8 \mathrm{yr}$ for length scales of $0.1 \mathrm{~mm}, 1 \mathrm{~m}$, and $10 \mathrm{~m}$, respectively. If the $\mathrm{CO}_{2}$ is in a loose regolith mixture or partially filled pore spaces, the thermal diffusivity may be as low as $3 \times 10^{-8} \mathrm{~m}^{2} \mathrm{~s}^{-1}$ [Kieffer and Zent, 1992], increasing the conduction timescales by an order of magnitude. The timescales to drive the phase change to vapor are a factor of a few longer (refer to the Stefan problem [Turcotte and Schubert, 1982]). Therefore, heating a parcel of buried solid $\mathrm{CO}_{2}$ to the equilibrium temperature on the geotherm is geologically instantaneous.

[13] Vapor diffusion rates through pore spaces in the Martian regolith are estimated following Moore et al. [1996], who estimated the flux of vapor through a porous regolith using Fick's Law,

$$
F_{v}=D \frac{\phi}{\tau} \frac{\partial N}{\partial Z}
$$

where $F_{v}$ is the vapor loss rate from the regolith in number of molecules $\mathrm{m}^{-2} \mathrm{~s}^{-1}, \partial N / \partial Z$ is the vapor density gradient between the $\mathrm{CO}_{2}$ at a depth $Z$ (in $\mathrm{m}$ ) and the atmosphere. The porosity, $\phi$, is assumed to be $10 \%$, and the tortuosity, $\tau$, is assumed to be 5 [after Moore et al., 1996]. The diffusion coefficient, $D$, is $(2 / 3) r_{p} \sqrt{(8 R T) /(M \pi)}$ in $\mathrm{m}^{2} \mathrm{~s}^{-1}$, where $r_{p}$ is the pore size, $M$ is the molecular mass of $\mathrm{CO}_{2}, 0.044$ $\mathrm{kg} \mathrm{mol}^{-1}, T$ is the temperature of the solid $\mathrm{CO}_{2}$ in $\mathrm{K}$, and $R$ is the gas constant. The calculated diffusivities, $D \phi / \tau$, are in good agreement with the values of $\mathrm{CO}_{2}$ diffusivity in terrestrial firn, about $10^{-6}-10^{-5} \mathrm{~m}^{2} \mathrm{~s}^{-1}$ for $0.1<\phi<0.5$ [Trudinger et al., 1997; Schwander et al., 1988], when $r_{p}=$ $0.5 \mu \mathrm{m}, \tau=5$, and $T=253 \mathrm{~K}$. The larger pore sizes used in our calculations reflect the assumption that the near-surface on Mars is best modeled as a brecciated regolith. The gradient $\partial N / \partial Z$ is calculated for the difference between the atmosphere and the equilibrium vapor density of solid $\mathrm{CO}_{2}$ at temperatures of $170 \mathrm{~K}$ and $210 \mathrm{~K}$, spanning the range of equilibrium temperatures where the gullies are observed (Figure 2). The vapor curve is given by $N(T)=\left[2.7 \times 10^{10} /\right.$ $(k T)] \exp (-2937.2 / T+0.01573 T)$ in molecules $\mathrm{m}^{-3}$ where $k$ is Boltzmann's constant [Moore et al., 1996; Lebofsky, 1975].

[14] The estimated times, $t_{h}$, to remove a $10 \mathrm{~m}$-thick layer (h) of solid $\mathrm{CO}_{2}$ from various depths are given in Table 1, where

$$
t_{h}=\frac{\rho_{s} h}{M N_{A} F_{v}}
$$

and $N_{A}$ is Avogadro's number. In the upper few hundred meters, the source region of the gullies, the timescales for removal are strongly temperature dependent, up to several thousands of years at $170 \mathrm{~K}$, to less than order $100 \mathrm{yr}$ at $210 \mathrm{~K}$. The timescales to remove a volatile from a mixture with the rock, instead of a separate layer, are of the same order of magnitude [Moore et al., 1996]. Thus, removal of buried $\mathrm{CO}_{2}$ is limited by vapor diffusion rather than conduction.

[15] Based on the preceding calculations, we conclude that crustal $\mathrm{CO}_{2}$ will equilibrate rapidly on geological timescales. Therefore, any condensed $\mathrm{CO}_{2}$ derived from an ancient greenhouse atmosphere would not persist in the present climate. Seasonal condensation in the present climate is limited to $\leq 1000 \mathrm{~kg} \mathrm{CO} \mathrm{Cm}^{-2}$ on the polar caps 
Table 1. Timescale in Years to Remove a 10-m-Thick Layer of Solid $\mathrm{CO}_{2}$ From the Specified Depth ${ }^{\mathrm{a}}$

\begin{tabular}{rccccc}
\hline & \multicolumn{2}{c}{$T_{\mathrm{CO}_{2}}=170 \mathrm{~K}$} & & \multicolumn{2}{c}{$T_{\mathrm{CO}_{2}}=210 \mathrm{~K}$} \\
\cline { 2 - 3 } \cline { 5 - 6 } Depth & $r_{p}=5 \mu \mathrm{m}$ & $r_{p}=100 \mu \mathrm{m}$ & & $r_{p}=5 \mu \mathrm{m}$ & $r_{p}=100 \mu \mathrm{m}$ \\
\hline $10 \mathrm{~m}$ & 700 & 40 & & 20 & 1 \\
$100 \mathrm{~m}$ & 7,000 & 400 & & 200 & 10 \\
\hline
\end{tabular}

${ }^{\mathrm{a}} T_{\mathrm{CO}_{2}}$ is the temperature of the buried solid $\mathrm{CO}_{2}$, spanning the range of equilibrium subsurface temperatures where the gullies are observed. The timescale is derived using Equations 3 and 4. Here $\phi=0.1, \tau=5$, and $r_{p}$ is the size of an average circular pore.

[Paige and Ingersoll, 1985] and will be much less on cold slopes at lower latitudes.

[16] Musselwhite et al. [2001] propose a model for $\mathrm{CO}_{2-}$ driven formation of the surface runoff features on Mars based on the idea that $\mathrm{CO}_{2}$ may condense into the regolith behind a cold, poleward-facing slope, filling the pore spaces with solid $\mathrm{CO}_{2}$ in the winter months. In the following spring, they propose that liquid $\mathrm{CO}_{2}$ would form as a result of thermal expansion of the solid $\mathrm{CO}_{2}$ in confining pore spaces and lead to rapid breakout of liquid $\mathrm{CO}_{2}$, driving a debris flow and forming the gully-like features.

[17] The model proposed by Musselwhite et al. [2001] is not supported by our calculations. First, the annual thermal skin depth is shallow, only a few meters for a regolith diffusivity of about $4 \times 10^{-7} \mathrm{~m}^{2} \mathrm{~s}^{-1}$, so the temperature a few meters behind a poleward-facing slope will be dominated by the average geotherm for that latitude. Next, the rates for vapor diffusion into the regolith are similar to the rates for diffusion out to the atmosphere, controlled primarily by the temperature gradient. The $\mathrm{CO}_{2}$ diffusion timescales (Table 1) show that it would take much longer than a single winter to fill regolith pore spaces at the latitudes where the gullies are observed. In addition, obliquity-driven surface temperature variations penetrating into the upper $\sim 1 \mathrm{~km}$ of the crust do not produce cool enough ground temperatures to significantly enhance diffusion-driven $\mathrm{CO}_{2}$ deposition [see Mellon and Phillips, 2001].

[18] Outgassing magmas are another source of $\mathrm{CO}_{2}$, and Kargel et al. [2000] suggest that outgassed $\mathrm{CO}_{2}$ could form significant amounts of solid or liquid $\mathrm{CO}_{2}$ in the crust. Most of the outgassed $\mathrm{CO}_{2}$ should escape to the atmosphere through volcanic processes, but assuming abundant intrusive magmatism on Mars, we estimate the supply and loss rates in the crust to determine whether it is likely that condensed $\mathrm{CO}_{2}$ could accumulate.

[19] If the total crustal emission of $\mathrm{CO}_{2}$ on Mars were comparable to the Earth, which emits about $10^{12} \mathrm{~mol} \mathrm{CO}_{2}$ $\mathrm{yr}^{-1}$ to the atmosphere [Gerlach, 1991; Jambon, 1994], a potential globally averaged thickness of $0.2 \mu \mathrm{m}$ of condensed $\mathrm{CO}_{2}$ could be trapped in the Martian crust per year. Estimates of the total magma production on Mars are a factor of 20 lower than on Earth, when scaled for the difference in planetary mass [Greeley and Schneid, 1991]. Although the intrusive component of magmatism on Mars may be underestimated, the total $\mathrm{CO}_{2}$ emitted from the crust should be less than or comparable to the Earth. Therefore, production of a global $10 \mathrm{~m}$-thick layer of condensible $\mathrm{CO}_{2}$ would require complete trapping of outgassed $\mathrm{CO}_{2}$ over a period of about $10^{8} \mathrm{yr}$.
[20] If the outgassed $\mathrm{CO}_{2}$ were not delivered directly to the atmosphere through volcanic processes, it would diffuse through the crust. The diffusion timescale through a relatively impermeable crust may be calculated using Equations 3 and 4 . For a crust with only $1 \%$ porosity, average pore size of $r_{p}=0.5 \mu \mathrm{m}$, and tortuosity of $\tau=5$, a $10 \mathrm{~m}$-thick layer of solid $\mathrm{CO}_{2}$ initially at a depth of $5 \mathrm{~km}$ would be removed on timescales of about $8 \times 10^{5}$ and $4 \times 10^{7}$ yr for equilibrium temperatures of 210 and $170 \mathrm{~K}$, respectively. Therefore, we find that the diffusive loss rates to the atmosphere are orders of magnitude faster than the supply from magmatism.

[21] In the case where the Martian crust contains significant amounts of $\mathrm{H}_{2} \mathrm{O}$, forming a near-surface cryosphere, $\mathrm{CO}_{2}$ diffusivities through a relatively impermeable ice layer should be similar to those calculated above (comparable to $1 \%$ porous terrestrial firn). Hence, the $\mathrm{CO}_{2}$ would escape from the ice over geological timescales.

[22] A crustal $\mathrm{CO}_{2}$ reservoir, unlike $\mathrm{H}_{2} \mathrm{O}$, is not selfsealing from the atmosphere. Solid $\mathrm{H}_{2} \mathrm{O}$ anywhere in the Martian crust must maintain a much smaller equilibrium $\mathrm{H}_{2} \mathrm{O}$ vapor pressure compared to $\mathrm{CO}_{2}$ (Figure 2). It is well established that a solid $\mathrm{H}_{2} \mathrm{O}$ plug at average subsurface temperatures is stable to vapor diffusion over billions of years under Martian conditions, given the assumption of abundant $\mathrm{H}_{2} \mathrm{O}$ in the regolith [e.g., Clifford, 1993; Moore et al., 1996; Mellon et al., 1997]. Instead of forming an equilibrating seal, a plug of solid $\mathrm{CO}_{2}$ in a pore, attempting to buffer a crustal $\mathrm{CO}_{2}$ reservoir from the atmosphere over geologic time, would quickly reach equilibrium geothermal temperatures and subsequently diffuse to the atmosphere at a geologically rapid rate, as shown in Table 1. Thus, $\mathrm{CO}_{2}$ cannot form a self-sealing reservoir in the Martian crust.

[23] In addition, even if the permeability of the crust were significantly lower than considered here, faulting and impacts make it extremely difficult to contain a near surface reservoir of condensed $\mathrm{CO}_{2}$ over $10^{8}$ yr. For example, the estimated impact flux on the surface of Mars produces about one 150 -m diameter crater per $\mathrm{km}^{2}$ every $10^{8}$ yr [Hartmann, 1999]. Because of the strong temperature dependence on the stability of $\mathrm{CO}_{2}$ in the crust (Figure 2), plausible focusing mechanisms, such as volcanism, would create an even more unstable environment than the average geotherm. Without a focusing mechanism, the rate of outgassing will not allow accumulation of solid $\mathrm{CO}_{2}$ in the crust, and certainly not liquid $\mathrm{CO}_{2}$, which requires significant pressurization to be stable. Hence, it is unlikely that outgassing magmas produce any solid or liquid $\mathrm{CO}_{2}$ in the crust in the present climate. We conclude that it is exceedingly improbable that a reservoir of condensed pure $\mathrm{CO}_{2}$ could be assembled in the regolith and available for surface modification processes such as gully formation.

\section{2. $\mathrm{CO}_{2}$ Clathrate Hydrate Formation}

[24] We have shown that near-surface crustal solid $\mathrm{CO}_{2}$ is limited to small quantities (under polar conditions) and derived primarily from the present atmosphere. Next, we examine the possible stability and formation of $\mathrm{CO}_{2}$ clathrate hydrate $\left(\mathrm{CO}_{2} \cdot 6 \mathrm{H}_{2} \mathrm{O}, \rho \sim 1100 \mathrm{~kg} \mathrm{~m}^{-3}\right)$ on Mars. Milton [1974] and Lambert and Chamberlain [1978] pointed out that $\mathrm{CO}_{2}$ clathrate hydrate would be stable under lithostatic pressures and Martian temperatures and suggested that its decomposition could drive surface modification processes 
including formation of chaotic terrain, flood channels, and debris flow features. More recently, Baker et al. [1991] suggest that $\mathrm{CO}_{2}$ clathrate may play an important role in episodic greenhouse events and Kargel et al. [2000] have proposed several mechanisms for $\mathrm{CO}_{2}$ clathrate formation on Mars.

[25] In the present climate, $\mathrm{CO}_{2}$ clathrate is stable with the atmosphere at temperatures a few degrees warmer than pure $\mathrm{CO}_{2}$. The $\mathrm{CO}_{2}$ clathrate hydrate stability field [Larson, 1955; Miller and Smythe, 1970; Sloan, 1998] is also shown in Figure 2 with the $\mathrm{CO}_{2}$ and $\mathrm{H}_{2} \mathrm{O}$ phase diagrams. Note that the presence of dissolved salts in $\mathrm{H}_{2} \mathrm{O}$ shrinks the stability field of the clathrate [Diamond, 1992, 1994]. Precipitation of clathrate from the atmosphere at equilibrium temperatures, in the polar regions or onto polewardfacing slopes, is fundamentally limited by the availability of $\mathrm{H}_{2} \mathrm{O}$ vapor in the atmosphere [Miller and Smythe, 1970; Kieffer, 2000], on average only about 10 precipitable microns. Seasonal deposition of $\sim 10 \mu \mathrm{m} \mathrm{m}^{-2}$ of clathrate would not be useful for surface modification processes.

[26] Long term storage of $\mathrm{CO}_{2}$ clathrates in the Martian crust, hypothetically formed in an ancient warmer climate, is limited by the removal rates in the present climate. The phase diagrams of $\mathrm{CO}_{2}$ and $\mathrm{CO}_{2}$ clathrate show that the stability of solid $\mathrm{CO}_{2}$ and $\mathrm{CO}_{2}$ clathrate are similar on Mars (Figure 2). Although neither the thermal conductivity nor specific heat capacity of $\mathrm{CO}_{2}$ clathrate have been measured, other clathrates have thermal conductivities similar to solid $\mathrm{CO}_{2}$ [Mellon, 1996; Ross and Kargel, 1998, and references therein] and specific heat capacities similar to solid $\mathrm{H}_{2} \mathrm{O}$ [Handa, 1986], which is about $1150 \mathrm{~J} \mathrm{~kg}^{-1} \mathrm{~K}^{-1}$ at $150 \mathrm{~K}$ [Dorsey, 1940]. Therefore, the thermal diffusivity of $\mathrm{CO}_{2}$ clathrate should be of the same order of magnitude as pure $\mathrm{CO}_{2}$. Hence, the timescales to equilibrate a parcel of $\mathrm{CO}_{2}$ clathrate to the temperature of surrounding rock in the crust are similar to the timescales calculated for pure $\mathrm{CO}_{2}$ in the previous section, essentially geologically instantaneous.

[27] Thus, removal of $\mathrm{CO}_{2}$ clathrate from the crust will be limited by diffusion of $\mathrm{CO}_{2}$ from the clathrate structure itself, which is governed by first-order kinetics [Henning et al., 2000; Adamson and Jones, 1971; Miller and Smythe, 1970]. Upon heating above the stability temperature $(\sim 150 \mathrm{~K})$, a parcel of crustal clathrate that is in contact with the atmosphere will begin to decompose into solid $\mathrm{H}_{2} \mathrm{O}$ and $\mathrm{CO}_{2}$ vapor. The timescale for decomposition of a surface layer (100's $\mu \mathrm{m}$ ) is hours [Miller and Smythe, 1970; Henning et al., 2000]. As the clathrate decomposes, a layer of pure $\mathrm{H}_{2} \mathrm{O}$ ice buffers the remaining clathrate and the decomposition is limited by $\mathrm{CO}_{2}$ diffusion through the $\mathrm{H}_{2} \mathrm{O}$ layer [Henning et al., 2000, and references therein].

[28] We estimate the rate of $\mathrm{CO}_{2}$ vapor diffusion through a $\mathrm{H}_{2} \mathrm{O}$ ice layer using the values from Schwander et al. [1988], where the diffusivity is $10^{-6}-10^{-5} \mathrm{~m}^{2} \mathrm{~s}^{-1}$ for porosities between $0.1-0.5$. Scaling the diffusivity linearly with the porosity, $\mathrm{CO}_{2}$ will be removed from a $1 \%$ porous, 1 -m layer of clathrate on timescales of roughly $1-100$ 's yr at temperatures of about $210-170 \mathrm{~K}$. Therefore, $\mathrm{CO}_{2}$ clathrate derived from an ancient greenhouse atmosphere would not persist to the present day.

[29] In the present climate, $\mathrm{CO}_{2}$ clathrate could only remain stable for geologically long periods in the south polar cap, although recent work by Mellon [1996] shows that little $\mathrm{CO}_{2}$ (only 10's mbar) may be sequestered in the present climate. The measured surface temperature of the north polar cap indicates that clathrates are not present [Ross and Kargel, 1998]. Formation of clathrate with $\mathrm{CO}_{2}$ from a non-atmospheric source is limited primarily by the supply of $\mathrm{CO}_{2}$. From the calculations in the previous section, we show that magmatic $\mathrm{CO}_{2}$ escapes quickly to the atmosphere. Small amounts of $\mathrm{CO}_{2}$ clathrate could form temporarily in the crust if the $\mathrm{CO}_{2}$ vapor were cooled to condensible temperatures $(\sim 150 \mathrm{~K})$, but accumulation of clathrate would be severely limited by the $\mathrm{CO}_{2}$ vapor supply rates, $<1 \mu \mathrm{m}$ $\mathrm{m}^{-2} \mathrm{yr}^{-1}$, even if abundant subsurface liquid or solid $\mathrm{H}_{2} \mathrm{O}$ were available. Formation of $\mathrm{CO}_{2}$ hydrate in the crust lacks efficient $\mathrm{CO}_{2}$ concentration mechanisms as pointed out by Max and Clifford [2001], who also note that over 99\% of terrestrial hydrates are based on methane, which are enabled by the abundance of mathanogenic bacteria.

[30] From the preceding arguments, we find that it is unlikely that bulk quantities ( $>10$ 's $\mu \mathrm{m} \mathrm{m}^{-2}$ ) of $\mathrm{CO}_{2}$ clathrate have formed from magmatic $\mathrm{CO}_{2}$ or current atmospheric sources. Kargel et al. [2000] also suggest that massive quantities of $\mathrm{CO}_{2}$ clathrate could have formed by direct precipitation in a formerly denser, warmer atmosphere or by progressive freezing of an ocean, increasing the ratio of dissolved $\mathrm{CO}_{2}$ to water above $1 / 6$ to allow clathrates to form. Direct precipitation requires a much more massive ancient climate, $>5$ bar, than suggested by recent models of climate evolution [Haberle et al., 1994; Fanale et al., 1992].

[31] In a freezing body of water, the solubility of $\mathrm{CO}_{2}$ is about $0.33 \mathrm{wt} \%$ at 1 bar $\mathrm{CO}_{2}$ vapor pressure [Lide, 2000]. If all of the $\mathrm{CO}_{2}$ remained dissolved in the liquid during the freezing process, the composition of the residual water would satisfy the $\mathrm{CO}_{2} / \mathrm{H}_{2} \mathrm{O}$ clathrate formation ratio of $1 / 6$ after freezing out $99 \%$ of the $\mathrm{H}_{2} \mathrm{O}$. The thickness of the water plus ice must be $\geq 300 \mathrm{~m}$ to reach the pressures required for clathrate formation, over 10 bar for temperatures near $0^{\circ} \mathrm{C}$ (Figure 2), which is difficult considering that the current Martian topography limits open bodies of water to $\leq 100$ 's m deep [Head et al., 1999]. For average mid-latitude and equatorial ground temperatures, the pressure on the clathrate from the overlying solid $\mathrm{H}_{2} \mathrm{O}$ will drop out of the stability field as the ice sublimates, and the clathrate will decompose at a rate limited by diffusion through the overlying solid ice or through pore spaces. Based on the decomposition timescales calculated above, any $\mathrm{CO}_{2}$ clathrate formed in a significantly different climate epoch on Mars would have decomposed during transition to the present climate. Hence, we find that it is extremely unlikely that $\mathrm{CO}_{2}$ clathrate is present in the Martian regolith in quantities that would affect surface modification processes.

\section{Gully Formation}

[32] Recently, several groups have proposed that the young gullies [Musselwhite et al., 2001; Hoffman, 2001, 2000b; Draper et al., 2000] and many larger-scale features on Mars [Hoffman, 2000a; Hoffman et al., 2001; Jöns, 2001; Parsons, 2001] may have formed from slope collapse related to the presence of subsurface liquid or solid $\mathrm{CO}_{2}$ and subsequent $\mathrm{CO}_{2}$ vapor-supported flow. Solid $\mathrm{CO}_{2}$ in open pore spaces would not contribute to a vapor-supported flow 


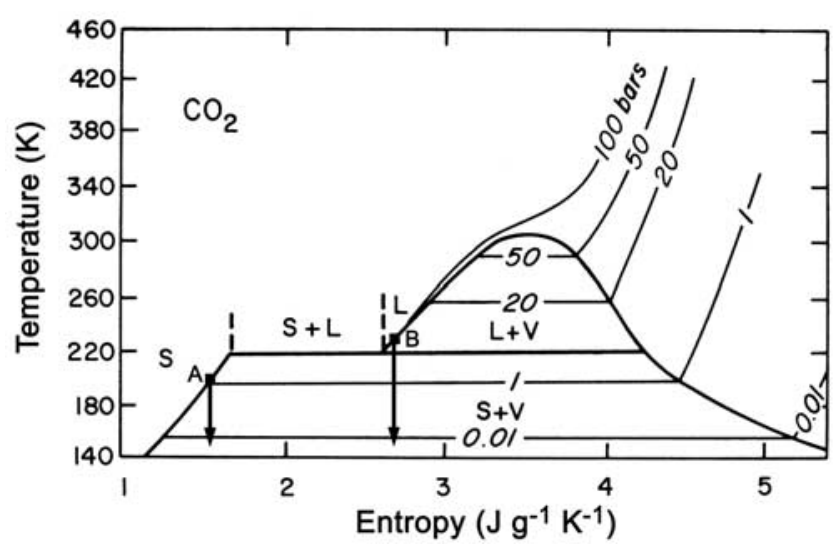

Figure 3. Temperature-entropy diagram for $\mathrm{CO}_{2}$. Points $\mathrm{A}$ and $\mathrm{B}$ and decompression arrows represent hypothetical solid and liquid $\mathrm{CO}_{2}$ reservoirs in the crust (Figure 2). Isentropic decompression follows a vertical line, and the amount of vapor produced upon decompression to Martian atmospheric pressure may be calculated using the lever rule. The vapor, liquid and solid stability fields are labeled V, L, and S respectively. Figure reprinted from Kieffer [1982].

since the $\mathrm{CO}_{2}$ would be in equilibrium with the atmosphere. Development of a vapor-supported flow, which might carve a channel, requires initial pressurization of $\mathrm{CO}_{2}$, for example, in a confined reservoir under lithostatic pressures. The calculations presented in Section 2 show the extreme difficulties in producing and maintaining a pressurized, condensed $\mathrm{CO}_{2}$ reservoir in the present climate. Next, we address the issue of whether a hypothetical $\mathrm{CO}_{2}$ vaporsupported flow agrees with the observations of recent fluidized debris flows on Mars.

\subsection{Decompression of Condensed $\mathrm{CO}_{2}$}

[33] We test the hypothesis that release of solid or liquid $\mathrm{CO}_{2}$ may form gully-like features on the surface of Mars by calculating the flow properties under the current climatic conditions. Points A and B in Figure 2 represent hypothetical solid and liquid $\mathrm{CO}_{2}$ reservoirs, respectively, near the source depth of the gullies, $\sim 200 \mathrm{~m}$, under a lithostatic pressure of about 20 bar. If suddenly exposed to atmospheric pressure, for instance by slope failure on a crater or valley wall, a rarefaction wave will travel into the condensed $\mathrm{CO}_{2}$, resulting in decompression and production of $\mathrm{CO}_{2}$ vapor. Decompression of $\mathrm{CO}_{2}$ and the accompanying phase changes are fast, occurring in seconds as the rarefaction wave travels through the $\mathrm{CO}_{2}$ at the sound speed of the condensed phase [Kieffer, 1982].

[34] The volume change accompanying the vapor generation will tend to accelerate the $\mathrm{CO}_{2}$ vapor into the atmosphere, in a manner similar to terrestrial volcanic eruptions. For likely conditions on Mars, the volume changes from vapor production will occur much more rapidly than volume changes due to heating by viscous dissipation or thermal conduction. The decompression process is therefore likely to be approximately isentropic.

[35] Following the method of Kieffer and Delany [1979] and Kieffer [1982], we can estimate the flow velocities for isentropic decompression of condensed $\mathrm{CO}_{2}$. Figure 3 plots the $\mathrm{CO}_{2}$ phase diagram in temperature-entropy (T-S) space. In this plot, isentropic decompression is represented by moving down a vertical line. The example reservoirs of solid and liquid $\mathrm{CO}_{2}$ are shown, point $\mathrm{A}$ at $200 \mathrm{~K}$ and 20 bar and point $\mathrm{B}$ at $225 \mathrm{~K}$ and 20 bar. Note that these initial conditions plot adjacent to the phase boundary because the pressure contours are very closely spaced near the solid and liquid boundary lines.

[36] Upon decompression from point $\mathrm{A}$, the solid $\mathrm{CO}_{2}$ passes into the solid+vapor equilibrium field. The decompression and production of vapor causes a drop in the temperature of the remaining solid. The mass fraction of vapor can be calculated by the lever rule. Decompression from point $\mathrm{A}$ to $7 \mathrm{mbar}$ produces about $7 \mathrm{wt} \%$ vapor. Liquid $\mathrm{CO}_{2}$ decompressing from point $\mathrm{B}$ crosses into the liquid+vapor stability field. At the triple point, represented by a horizontal line in $\mathrm{T}-\mathrm{S}$ space, the remaining liquid solidifies into $\mathrm{CO}_{2}$ "snow," initially at the triple point temperature. The solid $\mathrm{CO}_{2}$ will continue to cool by sublimation until it equilibrates with the atmosphere at about $150 \mathrm{~K}$. Decompression from point B to atmospheric pressures produces about $36 \mathrm{wt} \%$ vapor. The decompression scenario presented here is based on equilibrium thermodynamics, assuming that the $\mathrm{CO}_{2}$ vapor escapes to the atmosphere and does not build up a local equilibrium. Since the pressure gradient between an equilibrium crustal reservoir (lithostatic pressures and temperatures) and the atmosphere is large, this is considered a reasonable approximation.

[37] The velocity of the flow escaping to the atmosphere can be calculated from the change in enthalpy of the system resulting from the generation of vapor and the temperature drop upon decompression. This enthalpy change, $\Delta \mathrm{H}$, is given by

$$
\Delta H=H_{0}-x H_{v}-(1-x) H_{S}
$$

where $x$ is the vapor mass fraction, $H_{0}$ is the enthalpy of the original material, and $H_{v}$ and $H_{s}$ are the enthalpies of the

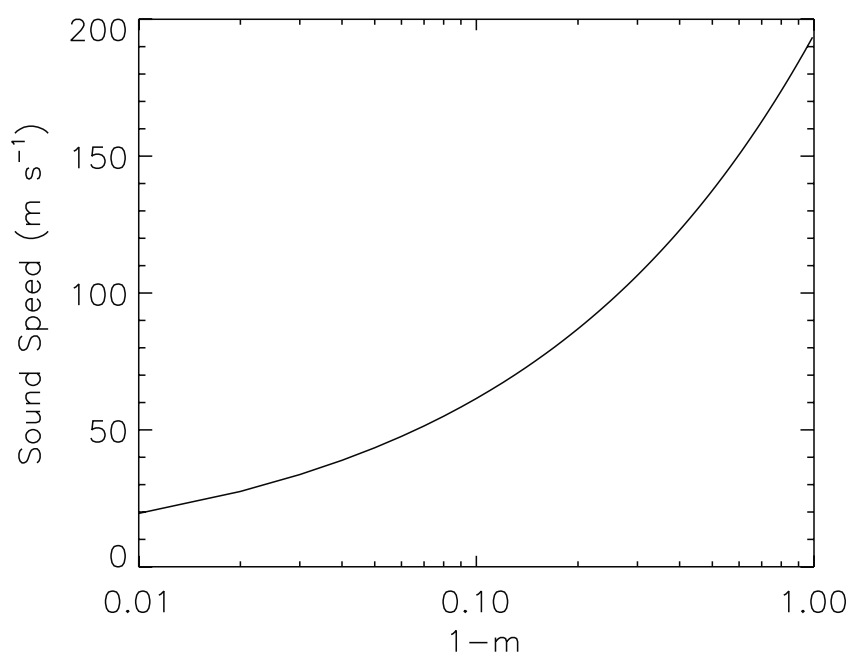

Figure 4. The sound speed (Equation 7) of a pseudogas $\mathrm{CO}_{2}$ vapor-regolith mixture as a function of the solid mass fraction, $m$. The exit velocity of a decompression-driven, $\mathrm{CO}_{2}$ vapor-supported flow is comparable to the sound speed of the pseudogas mixture and a factor of 10-100 times faster than liquid water-supported flows on Earth. 

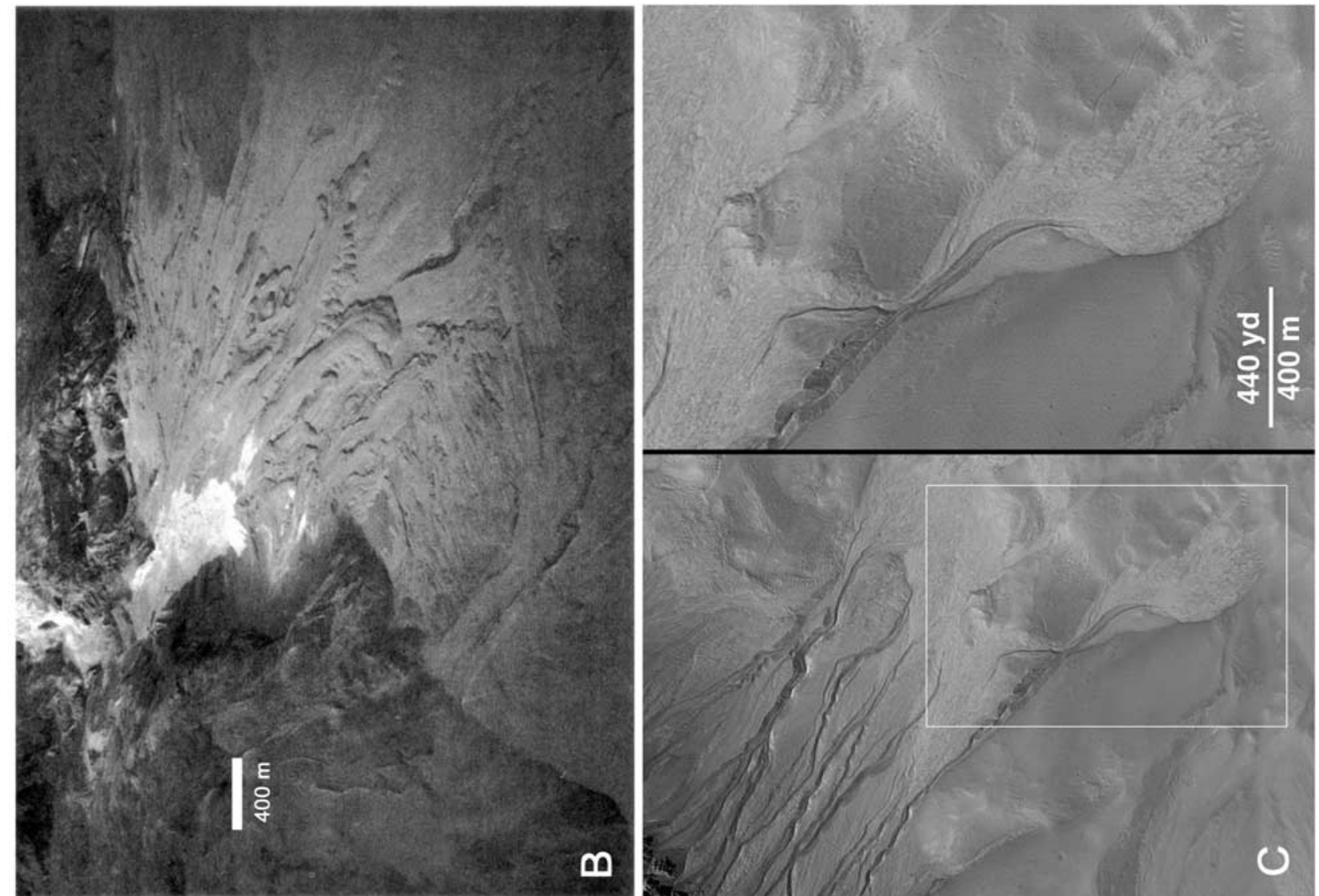

电

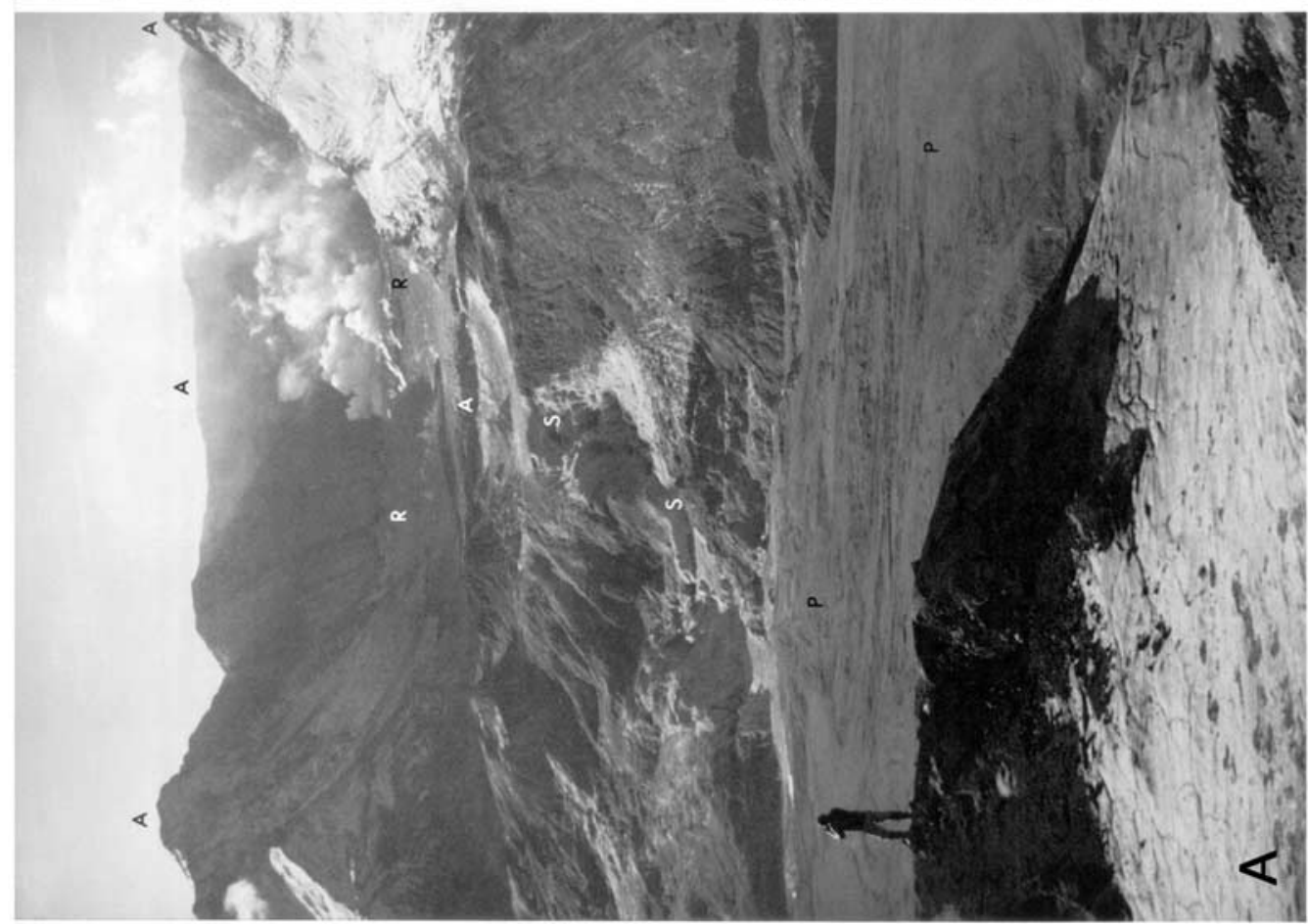


vapor and solid at 7 mbar. For the examples shown in Figure 3, the values of $H_{s}$ and $H_{v}$ are $17 \mathrm{~kJ} \mathrm{~kg}^{-1}$ and $620 \mathrm{~kJ}$ $\mathrm{kg}^{-1}$ at $7 \mathrm{mbar}$, respectively, and $H_{0}$ are $75 \mathrm{~kJ} \mathrm{~kg}^{-1}$ and 320 $\mathrm{kJ} \mathrm{kg}^{-1}$ for points A and B, respectively [Quinn and Jones, 1936]. Assuming that most of the energy is converted into kinetic energy of the expanding vapor mixture, the exit velocity $u$ is given by Smith et al. [1979]

$$
u^{2}=2 \Delta H
$$

for horizontal flow. So, for both examples in Figure 3, the exit velocity of the vapor is predicted to be a few $100 \mathrm{~m} \mathrm{~s}^{-1}$.

[38] In practice, the rapidly moving jet of $\mathrm{CO}_{2}$ vapor might be expected to entrain solid material, especially since any $\mathrm{CO}_{2}$ is likely to be stored in pores within the regolith, lowering the sound speed. The sound speed, $c$, of the resulting mixture is a good measure of both the exit velocity of the mixture and the rate at which the decompression wave will propagate into the interior of the $\mathrm{CO}_{2}$ reservoir [Kieffer, 1982]. The initial solid mass fraction, $m$, of the mixture will be high and the sound speed correspondingly low. For $1-$ $m \ll 1$ and the assumption of a pseudogas flow, the expressions of Rudinger [1980] can be used to obtain

$$
c^{2}=\frac{\Gamma R(1-m) T}{1-\epsilon^{2}}
$$

where $R$ is the gas constant (per $\mathrm{kg}$ ) of the $\mathrm{CO}_{2}, \Gamma$ is the heat capacity ratio of the mixture, and $T$ is the temperature. The volume fraction of the solid material, $\epsilon$, is given by

$$
\frac{\epsilon}{1-\epsilon}=\frac{m \rho_{g}}{(1-m) \rho_{s}}
$$

when the particles are in equilibrium with the gas. Here, $\rho_{g}$ is the vapor density and $\rho_{s}$ the density of the solids, $3000 \mathrm{~kg}$ $\mathrm{m}^{-3}$. For point A at $T=200 \mathrm{~K}$ the vapor will initially be at a pressure of $\sim 1$ bar (Figure 3 ), so $\rho_{g}$ is approximately $2.6 \mathrm{~kg}$ $\mathrm{m}^{-3}$ (the sound speed of the mixture is weakly dependent on $\rho_{g}$ ). Figure 4 shows the variation in sound speed as a function of $m$, assuming $\Gamma=1$. Thus, the sound speed is $>20 \mathrm{~m} \mathrm{~s}^{-1}$ for $1-m>0.01$.

[39] An upper bound on the likely initial value of the solid mass fraction, $m$, may be obtained as follows. If the $\mathrm{CO}_{2}$ is trapped in a reservoir with porosity $\phi$, the mass fraction of $\mathrm{CO}_{2}$ in the regolith, $m_{c}$, is

$$
m_{c}=\frac{\phi \rho_{c}}{\phi \rho_{c}+(1-\phi) \rho_{s}}
$$

where $\rho_{c}$ is the condensed $\mathrm{CO}_{2}$ density and $\rho_{s}$ the reservoir density. For $\phi=0.1$ and $\rho_{s}=3000 \mathrm{~kg} \mathrm{~m}^{-3}, m_{c}$ is approximately 0.05 . During decompression, a mass fraction $f$ of the solid $\mathrm{CO}_{2}$ will be converted to vapor, $7 \mathrm{wt} \%$ and 36 $\mathrm{wt} \%$ for points $\mathrm{A}$ and $\mathrm{B}$ respectively (Figure 3 ). Thus, if all the solid material is entrained with the expanding vapor, the mass fraction of vapor in the mixture is $\phi \times f=0.05 \times 0.07$ $\sim 0.4 \%$ and $0.05 \times 0.36 \sim 2 \%$, corresponding to $m \sim$ $0.98-0.99$. However, since some of the reservoir material is likely to be left in situ, this solid mass fraction, $m$, is an upper bound. Thus the exit velocity of the vapor-solids mixture is unlikely to be less than $20 \mathrm{~m} \mathrm{~s}^{-1}$ (Figure 4), in agreement with sound speeds calculated by Parsons [2000]. Parsons [2000] also notes that at these velocities, the flows are probably compressible and more complicated than the above analysis.

[40] On Earth, gullies are carved by water-supported debris flows with flow velocities of order $1 \mathrm{~m} \mathrm{~s}^{-1}$ [Brunsden and Prior, 1984]. The course of the narrow Martian channels are affected by the local slope topography [Malin and Edgett, 2000], over distances of 10's-100's m. The morphology implies a relatively slow flow velocity, since fast-flowing material may flow over low topographic features instead of being deflected by them. Terrestrial debris flows which produce morphologically similar features to those observed on Mars typically move 10-100 times slower than the estimated exit velocities for decompressing liquid $\mathrm{CO}_{2}$.

[41] Furthermore, if the mixture were originally ejected horizontally from a slope with velocities of order 20-100 m $\mathrm{s}^{-1}$, it will travel for a considerable distance before hitting the slope again. The down range distance is generally several hundred meters, enough to reach the crater or valley floor for many of the observed gully locales. Such a distance should be clearly visible in Mars Observer Camera images as a gap between the gully alcove and the point at which the deepest erosion begins. Although there are a few examples of discontinuities between the head alcove and channel, in general alcoves and channels are directly adjacent [Malin and Edgett, 2000]. As the initial decompression-driven jet wanes, erosion may occur closer to the source, but it would not have the same erosive ability as the faster-moving jet. Erosion from a waning jet is inconsistent with the observed channels which narrow with distance from the head alcove indicating stronger erosion near the source and deposition downslope [Schumm, 1977].

\subsection{Gas-Supported Flows}

[42] We now compare the morphologies of terrestrial pyroclastic flows to the Martian gullies and then evaluate the $\mathrm{CO}_{2}$ source requirements for a vapor-supported debris flow. Figure 5 compares the depositional morphologies of the 1980 Mount St. Helens pyroclastic flow deposits [Rowley et al., 1981] to a high-resolution image of the depositional apron of a Martian gully. The context image of the northern face of Mt. St. Helens (Figure 5a) shows several pyroclastic flow grooves and channels, including the light gray channel which forms the stairsteps feature. Vent

Figure 5. (opposite) Comparison of distal deposits from pyroclastic flows and Martian gullies. The amount of erosion and flow velocities for hypothetical $\mathrm{CO}_{2}$ vapor-supported flows is comparable to terrestrial pyroclastic flows. (A) Context view of northern face of Mt. St. Helens with pyroclastic flow channels and the stairsteps (S) feature leading to pumice plain (P) deposits. (B) Close-up of fresh pyroclastic flow deposits at the base of the stairsteps, forming narrow deposits with steep lateral levees (A,B [Rowley et al., 1981]). (C) Two high resolution views of a tapering channel (left side of Figure 1), showing deposition of debris over the outside of a bend in the channel following the local topography. [MGS MOC Release No. MOC2-241, 22 June 2000, NASA/JPL/MSSS.] 
velocities of large terrestrial pyroclastic flows may be as large as $60-200 \mathrm{~m} \mathrm{~s}^{-1}$ [Wilson and Head, 1981], comparable to the exit velocities calculated in the previous section. Most of the 1980 Mt. St. Helens pyroclastic events flowed along and eroded pre-existing stream channels [Rowley et al., 1981]. Erosion was greatest at the locations where the ground flow traveled fastest, almost $30 \mathrm{~m} \mathrm{~s}^{-1}$ near the steep base of the north face [Hoblitt, 1980]. The flow removed about $35 \mathrm{~m}$ from the stairsteps channel during the May 18, 1980, events [Rowley et al., 1981].

[43] In comparison, the anastamosing channels on Mars (Figure 5c) taper downslope indicating more erosion upslope and deposition downslope, consistent with liquidsupported flow. The example image from Mars shows the tapered end of a channel curving along local topography down to the crater floor (Figure $5 \mathrm{c}$ ). The deposition occurs in a fan overflowing the outer bank of the curve as expected in liquid-supported flow within a channel [Schumm, 1977].

[44] The fluidization of the particles in a pyroclastic flow is maintained by heating air that is entrained at the front of the flow, and pyroclastic flows deposit their load as the air escapes from the sides and top of the flowing air-particle mixture. In the Mt. St. Helens example, the pyroclastic flow at the base of the stairsteps (Figure 5b) formed the narrow deposits quickly as the velocity of the flow decreased suddenly upon reaching the pumice plain [Rowley et al., 1981] causing rapid loss of fluidization of the solids and forming lateral levees [Wilson and Head, 1981]. A similar velocity change can be expected when the flows on Mars reach the valley or crater floor (Figure 5c), but the characteristics of the deposits are markedly different (compare Figures $5 \mathrm{~b}$ and $5 \mathrm{c}$ ). We conclude that the morphological differences between terrestrial pyroclastic flows and the gullies on Mars are significant.

[45] Next, we estimate the mass of $\mathrm{CO}_{2}$ vapor necessary to support the mass of a typical debris apron on Mars. Recent work indicates that turbidity currents and gas-supported flows on Earth have small solid volume fractions. Dade and Huppert [1995] find that the Taupo ignimbrite flow probably contained $0.3 \%$ by volume solids near the vent (and less at greater distances). For the analogous Martian case, the solids are likely to fall out more rapidly because 1) the density of the ambient atmosphere is lower and 2) the solids and gas are not hot (unlike pyroclastic material). Malin and Edgett [2000] estimate the volume of a single debris apron at $\sim 10^{4} \mathrm{~m}^{3}$. If this apron was the result of a vapor-supported Martian flow, a likely solid volume fraction of $0.1 \%$ implies a $\mathrm{CO}_{2}$ gas volume of at least $\sim 10^{7} \mathrm{~m}^{3}$. The equivalent mass of $\mathrm{CO}_{2}$, using the ideal gas law at $7 \mathrm{mbar}$ and $200 \mathrm{~K}$, is about $10^{5} \mathrm{~kg}$. Without a mechanism to maintain the fluidization of the flow, such as heating of entrained air in the case of terrestrial pyroclastic flows, the initial amount of $\mathrm{CO}_{2}$ vapor must be greater than $10^{5} \mathrm{~kg}$, since vapor is constantly escaping the debris-gas mixture as it flows along the surface.

[46] In the model proposed by Musselwhite et al. [2001] and Hoffman [2001, 2000b], the source of the $\mathrm{CO}_{2}$ vapor in the flow is depressurization of liquid or solid $\mathrm{CO}_{2}$, and the fluidization of the flow is sustained by subsequent frictional heating of entrained solid $\mathrm{CO}_{2}$ [Hoffman, 2001]. We find that frictional heating of entrained $\mathrm{CO}_{2}$ solid is unlikely to produce significant $\mathrm{CO}_{2}$ vapor. The latent heat of sublimation of $\mathrm{CO}_{2}$ solid is $613 \mathrm{~kJ} \mathrm{~kg}^{-1}$. If all of the potential energy of a debris flow from a height of $1 \mathrm{~km}$ were used to vaporize $\mathrm{CO}_{2}$, the available energy would be $3.7 \mathrm{~kJ}$ per $\mathrm{kg}$ of regolith. If the mass fraction of $\mathrm{CO}_{2}$ in the flow were about $10 \%$, then the energy available for vaporizing the solid $\mathrm{CO}_{2}$ is around $37 \mathrm{~kJ}$ per $\mathrm{kg}$ of $\mathrm{CO}_{2}$. A maximum of $6 \mathrm{wt} \%$ of $\mathrm{CO}_{2}$ could be converted to vapor, similar to the mass fraction of vapor produced from decompression of solid $\mathrm{CO}_{2}$ (point $\mathrm{A}$, Figure 3). Thus, most of the vapor needed to support the observed volume of particles must be generated from the initial decompression process.

[47] The decompression of $\mathrm{CO}_{2}$ from points $\mathrm{A}$ and $\mathrm{B}$ (Figure 3) yielded about $7 \mathrm{wt} \%$ and $36 \mathrm{wt} \%$ vapor, respectively. Therefore, to generate $10^{5} \mathrm{~kg}$ of $\mathrm{CO}_{2}$ vapor, an initial reservoir of at least $10^{6} \mathrm{~kg}$ of solid or $3 \times 10^{5} \mathrm{~kg}$ liquid $\mathrm{CO}_{2}$ must be depressurized. Since condensed $\mathrm{CO}_{2}$ reservoirs under lithostatic pressures and temperatures must be isolated from the atmosphere to remain stable, each gully flow event must come from a protected reservoir, with more than $10^{5}-10^{6} \mathrm{~kg}$ of liquid or solid $\mathrm{CO}_{2}$.

[48] In the best case scenario, condensed $\mathrm{CO}_{2}$ would fill the pore spaces in the wall of the slope behind a strong sealing barrier. If the reservoir filled $10 \%$ of the regolith, a single gully source reservoir of $10^{6} \mathrm{~kg} \mathrm{CO}_{2}$ would draw from a minimum regolith volume of $10^{4} \mathrm{~m}^{3}$. Since the gullies are closely spaced (10's-100's m) and show evidence of repeated flow events [Malin and Edgett, 2000], $\mathrm{CO}_{2}$ source reservoirs would have to be replenished. The calculations in Section 2 show that the quantities of $\mathrm{CO}_{2}$ required to support a single flow could not be replenished in the present climate. Therefore, if the $\mathrm{CO}_{2}$ hypothesis were correct, all of the $\mathrm{CO}_{2}$ for all of the gullies must have originated from nearby reservoirs formed in an ancient climate. The $\mathrm{CO}_{2}$ diffusion timescales to the atmosphere and disruptions from faulting and cratering are impossible to reconcile with this hypothesis; therefore, we conclude that $\mathrm{CO}_{2}$ vapor-supported flows could not form the young gully features on Mars.

\section{Summary}

[49] After examining the geologic processes that may emplace $\mathrm{CO}_{2}$ in the Martian crust and its stability in the present climate, we find that neither solid or liquid $\mathrm{CO}_{2}$ nor $\mathrm{CO}_{2}$ clathrate can be accumulated in bulk quantities. Subsurface solid or liquid $\mathrm{CO}_{2}$ formed in a hypothesized early, more massive atmosphere would not persist to the present day because diffusion rates through the crust are much shorter than the billion-year timescales for climate change. $\mathrm{CO}_{2}$ condensation in the current climate is limited to $\leq 1000$ $\mathrm{kg} \mathrm{m}^{-2}$ in the polar regions, and outgassed $\mathrm{CO}_{2}$ from magmas would escape to the atmosphere at geologically fast rates. Therefore, except for seasonal polar caps, it is extremely unlikely that $\mathrm{CO}_{2}$ has driven surface modification processes in the present climate.

[50] We find that the mass of $\mathrm{CO}_{2}$ required to support a single debris flow to be larger than plausible $\mathrm{CO}_{2}$ content in the present day crust. Furthermore, sudden exposure of condensed $\mathrm{CO}_{2}$ to the surface probably produces volcanic-like jets of $\mathrm{CO}_{2}$ vapor that are unlikely to form the observed tapering V-shaped channels and depositional 
aprons. We conclude that the gullies were not formed by $\mathrm{CO}_{2}$-based flows.

[51] In the absence of other possibilities, liquid water is the most likely formation fluid for the surface runoff features. Since liquid water is not stable near the surface, the formation mechanism of these features probably involves rapid melting or transport of liquid water from depth. Even though we do not know the absolute amount of water available in the regolith, $\mathrm{H}_{2} \mathrm{O}$ vapor or liquid migration can transport $\mathrm{H}_{2} \mathrm{O}$ near to the surface [Clifford, 1993; Mellon et al., 1997]. If liquid water could be brought to the surface, it would have no difficulty in carving the observed gullies, as water-supported debris flows on Earth easily reproduce the morphology of the observed gullies. Unlike $\mathrm{CO}_{2}$-based formation, the issues related to melting or transport of water to form gullies are tractable problems with geologically plausible solutions [cf. Knauth et al., 2000; Saunders and Zurek, 2000; Doran and Forman, 2000; Gaidos, 2001; Mellon and Phillips, 2001].

[52] Acknowledgments. The authors thank A. Albee, S. Byrne, E. Gaidos, A. Ingersoll, M. Richardson, D. Stevenson, and A. Vasavada, for their helpful discussions and comments, and M. Hecht, for his thoughtful review and suggestions. F. N. acknowledges support from NASA grant NAG5-10587 and Magdalene College, Cambridge. S.T.S. was supported by NASA/Goddard grant NAG5-10198. Contribution number 8866, Division of Geological and Planetary Sciences, California Institute of Technology, Pasadena, CA 91125.

\section{References}

Adamson, A., and B. Jones, Physical adsorption of vapors on ice, IV, Carbon dioxide, J. Colloid Interface Sci., 37, 831-835, 1971.

Armistead, G. A., The occurrence and geological implications of carbon dioxide clathrate hydrate on Mars, Master's thesis, Univ. of Houston, Houston, Tex., 1979.

Baker, V., R. Strom, J. Dohm, V. Gulick, J. Kargel, G. Komatsu, G. Ori, and J. Rice Jr., Mars: Oceanus Borealis, ancient glaciers, and the MEGAOUTFLO hypothesis, in Proc. Lunar Planet. Sci. Conf. 31st, abstract 1863,2000

Baker, V. R., R. G. Strom, V. C. Gulick, J. S. Kargel, G. Komatsu, and V. S. Kale, Ancient oceans, ice sheets and the hydrological cycle on Mars, Nature, 352, 589-594, 1991.

Brunsden, D., and D. B. Prior (Eds.), Slope Instability, John Wiley, New York, 1984.

Carr, M. H., Water on Mars, Oxford Univ. Press, New York, 1996.

Clifford, S. M., A model for the hydrologic and climatic behavior of water on Mars, J. Geophys. Res., 98, 10,973-11,016, 1993.

Dade, W. B., and H. E. Huppert, Runout and fine-sediment deposits of axisymmetrical turbidity currents, J. Geophys. Res., 100(C9), 18,597$18,609,1995$.

Diamond, L., Stability of $\mathrm{CO}_{2}$ clathrate hydrate $+\mathrm{CO}_{2}$ liquid $+\mathrm{CO}_{2}$ vapour+aqueous $\mathrm{KCl}-\mathrm{NaCl}$ solutions-Experimental determination and application to salinity estimates of fluid inclusions, Geochim. Cosmochim. Acta, $56,273-280,1992$.

Diamond, L., Salinity of multivolatile fluid inclusions determined from clathrate hydrate stability, Geochim. Cosmochim. Acta, 58, 19-41, 1994.

Dobrovolskis, A., and A. P. Ingersoll, Carbon dioxide-water clathrate as a reservoir of $\mathrm{CO}_{2}$ on Mars, Icarus, 26, 353-357, 1975.

Doran, P., and S. Forman, Ideas about the surface runoff features on Mars, Science, 290, 711-714, 2000.

Dorsey, N. E., (Ed.), Properties of Ordinary Water-Substance, Reinhold, New York, 1940.

Draper, D. S., J. Jones, and J. Longhi, Martian weeping layers and the nature of volatile reservoirs in the upper Martian crust, Eos Trans. $A G U, 81$, Fall Meet. Suppl., P61B-04, 2000.

Fanale, F., J. Salvail, A. Zent, and S. Postawko, Global distribution and migration of subsurface ice on Mars, Icarus, 67, 1-18, 1986.

Fanale, F. P., S. E. Postawko, J. B. Pollack, M. H. Carr, and R. O. Pepin, Mars: Epochal climate change and volatile history, in Mars, edited by $\mathrm{H}$. H. Kieffer et al., pp. 1135-1179, Univ. of Ariz. Press, Tucson, 1992.

Gaidos, E. J., Cryovolcanism and the recent flow of liquid water on Mars, Icarus, 153, 218-223, 2001.
Gerlach, T. M., Present-day $\mathrm{CO}_{2}$ emissions from volcanoes, Eos Trans. $A G U, 72,249-256,1991$.

Greeley, R., and B. D. Schneid, Magma generation on Mars: Amounts, rates, and comparisons with Earth, Moon, and Venus, Science, 254, 996-998, 1991 .

Haberle, R., D. Tyler, C. Mckay, and W. Davis, A model for the evolution of $\mathrm{CO}_{2}$ on Mars, Icarus, 109, 102-120, 1994.

Handa, Y. P., Calorimetric determinations of the compositions, enthalpies of dissociation, and heat capacities in the range 85 to $270 \mathrm{~K}$ for clathrate hydrates of xenon and krypton, J. Chem. Thermodyn., 18, 891-902, 1986.

Hartmann, W., Martian cratering, VI, Crater count isochrons and evidence for recent volcanism from Mars Global Surveyor, Meteorit. Planet. Sci., 34, 167-177, 1999.

Head, J. W., H. Hiesinger, M. A. Ivanov, M. A. Kreslavsky, S. Pratt, and T. B. J., Possible ancient oceans on Mars: Evidence from Mars Orbiter Laser Altimeter data, Science, 286, 2134-2137, 1999.

Hecht, M. H., Metastability of liquid water on Mars, Icarus, 156, 373-386, 2002.

Henning, R., A. Schultz, V. Thieu, and Y. Halpern, Neutron diffraction studies of $\mathrm{CO}_{2}$ clathrate hydrate: Formation from deuterated ice, J. Phys. Chem. A, 104, 5066-5071, 2000.

Hoblitt, R. P., Observations of pyroclastic flows of July 22 and August 7 , 1980, Mount St. Helens, Washington, Eos Trans. AGU, 61, 1137-1138, 1980.

Hoffman, N., White Mars: A new model for Mars' surface and atmosphere based on $\mathrm{CO}_{2}$, Icarus, 146, 326-342, 2000a.

Hoffman, N., Ideas about the surface runoff features on Mars, Science, 290, $711-714,2000 \mathrm{~b}$.

Hoffman, N., Fresh polar channels on Mars as evidence of continuing $\mathrm{CO}_{2}$ vapour-supported density flows, Proc. Lunar Planet. Sci. Conf. 32nd, abstract 2171, 2001.

Hoffman, N., K. L. Tanaka, J. S. Kargel, and W. B. Banderdt, Emplacement of a debris ocean on Mars by regional-scale collapse and flow at the crustal dichotomy, Proc. Lunar Planet. Sci. Conf. 32nd, abstract 1584, 2001.

Jambon, A., Earth degassing and large-scale geochemical cycling of volatile elements, in Volatiles in Magmas, Rev. Mineral., vol. 30, pp. 479517, Mineral. Soc. of Am., Washington, D. C., 1994.

James, P. B., H. H. Kieffer, and D. A. Paige, The seasonal cycle of carbon dioxide on Mars, in Mars, pp. 934-968, edited by H. H. Kieffer et al., Univ. of Ariz. Press, Tucson, 1992.

Jöns, H., Morphologic hints for $\mathrm{CO}_{2}$ as active agent in Martian relief dynamics, Proc. Lunar Planet. Sci. Conf. 32nd, abstract 1102, 2001.

Kargel, J. S., K. L. Tanaka, V. R. Baker, G. Komatsu, and D. R. MacAyeal, Formation and dissociation of clathrate hydrates on Mars: Polar caps, northern plains, and highlands, Proc. Lunar Planet. Sci. Conf. 31st, abstract 1891, 2000 .

Kieffer, H., Mars south polar spring and summer temperatures: A residual $\mathrm{CO}_{2}$ frost, J. Geophys. Res., 84, 8263-8288, 1979.

Kieffer, H., Clathrates are not the culprit, Science, 287, 1753-1753, 2000.

Kieffer, H., T. Titus, K. Mullins, and P. Christensen, Mars south polar spring and summer behavior observed by TES: Seasonal cap evolution controlled by frost grain size, J. Geophys. Res., 105, 9653-9699, 2000.

Kieffer, H. H., and A. P. Zent, Quasi-periodic climate change on Mars, in Mars, edited by H. H. Kieffer et al., pp. 1180-1218, Univ. of Ariz. Press, Tucson, 1992.

Kieffer, S. W., Dynamics and thermodynamics of volcanic eruptions: Implications for the plumes on Io, in Satellites of Jupiter, pp. 647-723, Univ. of Ariz. Press, Tucson, 1982.

Kieffer, S. W., and J. M. Delany, Isentropic decompression of fluids from crustal and mantle pressures, J. Geophys. Res., 84, 1611-1620, 1979.

Knauth, L., S. Klonowski, and B. Donald, Ideas about the surface runoff features on Mars, Science, 290, 711-714, 2000.

Komatsu, G., J. S. Kargel, V. R. Baker, R. G. Strom, G. G. Ori, C. Mosangini, and K. L. Tanaka, A chaotic terrain formation hypothesis: Explosive outgas and outflow by dissociation of clathrate on Mars, Proc. Lunar Planet. Sci. Conf. 31st, abstract 1434, 2000.

Kravchenko, Y., and I. Krupskii, Thermal conductivity of solid $\mathrm{N}_{2} \mathrm{O}$ and $\mathrm{CO}_{2}$, Sov. J. Low Temp. Phys., 12, 46-48, 1986.

Lambert, R., and V. Chamberlain, $\mathrm{CO}_{2}$ permafrost and Martian topography, Icarus, 34, 568-580, 1978.

Larson, S. D., Phase studies of the two-component carbon dioxide-water system involving the carbon dioxide hydrate, Ph.D. thesis, Univ. of Ill., Urbana, 1955.

Lebofsky, L. A., Stability of frosts in the solar system, Icarus, 25, 205217, 1975.

Lide, D. R., (Ed.), CRC Handbook of Chemistry and Physics, CRC Press, Boca Raton, Fla., 2000.

Longhi, J., Low-temperature phase relations in the $\mathrm{CO}_{2}-\mathrm{H}_{2} \mathrm{O}$ system with application to Mars, Proc. Lunar Planet. Sci. Conf. 31st, abstract 1518, 2000. 
Malin, M. C., and K. S. Edgett, Evidence for recent groundwater seepage and surface runoff on Mars, Science, 288, 2330-2325, 2000.

Max, M. D., and S. M. Clifford, Initiation of Martian outflow channels: Related to the dissociation of gas hydrate?, Geophys. Res. Lett., 28, 1787-1790, 2001.

Mellon, M., Limits on the $\mathrm{CO}_{2}$ content of the Martian polar deposits, Icarus, 124, 268-279, 1996.

Mellon, M., B. Jakosky, and S. Postawko, The persistence of equatorial ground ice on Mars, J. Geophys. Res., 102, 19,357-19,369, 1997.

Mellon, M. T., and R. J. Phillips, Recent gullies on Mars and the source of liquid water, J. Geophys. Res., 106, 23,165-23,180, 2001.

Miller, S. L., The nature and occurrence of clathrate hydrates, Natural Gases in Marine Sediments, Marine Science, vol. 3, pp. 151-177, Plenum, New York, 1974.

Miller, S. L., and W. D. Smythe, Carbon dioxide clathrate in the Martian ice cap, Science, 170, 531-533, 1970 .

Milton, D. J., Carbon dioxide hydrate and floods on Mars, Science, 183, 654-656, 1974

Moore, J., M. Mellon, and A. Zent, Mass wasting and ground collapse in terrains of volatile-rich deposits as a solar system-wide geological process: The pre-Galileo view, Icarus, 122, 63-78, 1996.

Musselwhite, D., T. Swindle, and J. Lunine, Liquid $\mathrm{CO}_{2}$ breakout and the formation of recent small gullies on Mars, Geophys. Res. Lett., 28, $1283-$ 1285,2001

Nye, J., W. Durham, P. Schenk, and J. Moore, The instability of a south polar cap on Mars composed of carbon dioxide, Icarus, 144, 449-455, 2000.

Paige, D., and A. Ingersoll, Annual heat-balance of Martian polar capsViking observations, Science, 228, 1160-1168, 1985.

Parsons, J., Are fast-growing Martian dust storms compressible?, Geophys. Res. Lett., 27, 2345-2348, 2000.

Parsons, J. D., Wet evidence for a dry Mars, Proc. Lunar Planet. Sci. Conf. 32nd, abstract 1256, 2001.

Quinn, E. L., and C. L. Jones, Carbon Dioxide, Reinhold, New York, 1936.

Ross, R. G., and J. S. Kargel, Thermal conductivity of solar system ices, with special reference to Martian polar caps, in Solar System Ices, edited by B. Schmitt, C. de Bergh, and M. Festou, pp. 33-62, Kluwer Acad., Norwell, Mass., 1998.

Rowley, P. D., M. A. Kuntz, and N. S. Macleod, Pyroclastic-flow deposits, in The 1980 Eruptions of Mount St. Helens, Washington, U.S. Geol. Surv. Prof. Pap., 1250, 489-512, 1981.

Rudinger, G., Fundamentals of Gas-Particle Flow, Elsevier Sci., New York, 1980.

Saunders, R., and R. Zurek, Ideas about the surface runoff features on Mars, Science, 290, 711-714, 2000.

Schumm, S. A., The Fluvial System, John Wiley, New York, 1977.

Schwander, J., B. Stauffer, and A. Sigg, Air mixing in firn and the age of the air at pore close-off, Ann. Glaciol., 10, 141-145, 1988.

Sloan, E., Jr., Clathrate Hydrates of Natural Gases, 2nd ed., Marcel Dekker, New York, 1998.

Smith, B., E. Shoemaker, S. Kieffer, and A. Cook, The role of $\mathrm{SO}_{2}$ in volcanism on Io, Nature, 280, 738-743, 1979.

Span, R., and W. Wagner, A new equation of state for carbon dioxide covering the fluid region from the triple point temperature to $1100 \mathrm{~K}$ at pressures up to $800 \mathrm{MPa}, J$. Phys. Chem. Ref. Data, 25, 1509-1596, 1996.

Trudinger, C., I. Enting, D. Etheridge, R. Francey, V. Levchenko, L. Steele, D. Raynaud, and L. Arnaud, Modeling air movement and bubble trapping in firn, J. Geophys. Res., 102, 6747-6763, 1997.

Turcotte, D. L., and G. Schubert, Geodynamics, John Wiley, New York, 1982.

Wagner, W., A. Saul, and A. Pruss, International equations for the pressure along the melting and along the sublimation curve for ordinary water substance, J. Phys. Chem. Ref. Data, 23, 515-527, 1994.

Washburn, E. W., C. J. West, and N. E. Dorsey (Eds.), International Critical Tables, McGraw-Hill, New York, 1929.

Wilson, L., and J. W. Head, Morphology and rheology of pyroclastic flows and their deposits, and guidelines for future observations, in The 1980 Eruptions of Mount St. Helens, Washington, U.S. Geol. Surv. Prof. Pap., 1250, 513-524, 1981 .

F. Nimmo, Department of Geological Sciences, University College London, Gower Street, London WC1E 6BT, UK. (nimmo@esc.cam.ac.uk) S. T. Stewart, Geophysical Laboratory, Carnegie Institution of Washington, 5251 Broad Branch Road, NW, Washington, DC 20015, USA. (sstewart@gl.ciw.edu) 